\title{
Evaluation and Research on Static and Dynamic Acid Generation of Waste Rock at Dexing Copper Mine in Different Years
}

\author{
Qiong Wang ${ }^{1, a}$, Yi Liü,b, Yuli Han ${ }^{3, c}$, Lianbi Zhou,d* \\ ${ }^{1}$ Beijing General Research Institute of Mining \& Metallurgy, China \\ ${ }^{2}$ China Science and Technology Museum, China \\ ${ }^{3}$ College of forestry, Beijing Forestry University, China \\ ${ }^{4}$ Beijing General Research Institute of Mining \& Metallurgy, China \\ a'wangqiong426@126.com, bliuyi@cstm.org.cn, ${ }^{\mathrm{c}}$ hanyuli2011@163.com, ${ }^{\mathrm{d}}$ \\ zhoulianbi@aliyun.com
}

Keywords: acid mine drainage; waste rock; Static evaluation; Dynamic evaluation

Abstract. Waste rock and tailings of a mine generate acid mine drainage due to oxidization during long-term stacking, and this may cause serious harm to the environment. 1-year-old, 5-year-old, 10-year-old and 20-year-old waste rock of Dexing Copper Mine are chosen in the experiment for acid generation research. The static evaluation result shows that the 4 types of waste rock have the acid generating potential, and 3 types (except for 1-year-old waste rock) have generated acid. The 9-month dynamic evaluation result indicates: the $\mathrm{pH}$ values of waste rock of 4 different ages show remarkable negative correlation, the detected ions are mainly of fluorides, $\mathrm{Cu}^{2+}, \mathrm{Zn}^{2+}, \mathrm{SO}_{4}{ }^{2-}$ and $\mathrm{Fe}^{3+}$. 1-year-old waste rock doesn't generate acid during the entire experiment, the acid generation of 5-year-old and 10 -year-old waste rock is stable, but that of 20-year-old waste rock is slow. Thus the acid generation process of waste rock can be inferred as: no acid generation - high-rate acid generation - stable acid generation - lower-rate acid generation.

\section{Introduction}

Sulfide minerals (usually $\mathrm{FeS}_{2}$ ) generate acid upon oxidation due to corrosion in rainfall or gushing water in pits, and subsequently react with the existing compounds in minerals and release metallic ions therein and finally acid mine wastewater is formed. As acid wastewater of mines features high acidity, high concentration of heavy metallic ions, large quantity of generation and long lasting time, and big fluctuation with seasonal and ore deposit conditions and as well as water yield, it has attracted wide concerns of people around the world. Acid mine wastewater may corrode pipelines and mining equipment if discharged without treatment, and seriously damage the ecological environment of water bodies if it runs into rivers, and thus affect the normal growth of aquatic organisms; and it may damage the granular structure of soil when it runs into soil, and cause plants unable to normally absorb water and nutrients ${ }^{[1,2]}$; and finally affect the health of man directly through metal enrichment ${ }^{[3]}$. As most metal mines are of primary sulfide deposits in China and a considerable proportion of coal mines are of medium/high-sulfur coal mines, acid waste water exists extensively in the mines and during coal mining in China.

Dexing Copper Mine is located in Dexing City, Shangrao Region of Jiangxi Province, one of the largest porphyry open-pit copper mine in China. Since the mining commenced in 1958, the acid mine drainage generated has caused severe acidification and greatly affected the ecological environment of water bodies. As for acid mine drainage, prevention is much more important than treatment. The first step of prevention is to predict the potential of waste rock and tailings so as to better control the generation of acid mine drainage at the source ${ }^{[4]}$. At present, prediction methods mainly include static prediction and dynamic prediction; therein, static prediction is a rapid and low-cost method to evaluate the acid generating potential of solid wastes of mines, mainly including acid-base account (ABA) and net acid generation (NAG) tests. However, static prediction also has its limitation, e.g. unable to decide 
whether some wastes generate acid; and meanwhile, static prediction also cannot reflect the dynamic acid generaing process of waste rock and tailings. Whereas, dynamic leaching test can better evaluate the long-term acid generating potential and the law of acid generation of waste rock ${ }^{[5,6]}$.

Therefore, waste rock of different ages (1-year-old, 5-year-old and 20-year-old) are selected for chemical composition analysis and static evaluation in this paper, and a 9-month leaching test is carried out to dynamically monitor the acid generation of waste rock and the release of metallic ions, and infer the long-term law of acid generation of waste rock on such basis, so as to provide a theoretical basis for the prevention and treatment of acid mine drainage.

\section{Materials and methods}

Sampling and processing. Waste rock are taken from Dexing Copper Mine, ground by crusher to a size $<5 \mathrm{~mm}$. The samples can be weighed and taken directly for dynamic leaching, but it needs further screening by 200 -mesh sieve $(<75 \mu \mathrm{m})$ for static evaluation. Chemical compositions of waste rock are analyzed before and after test.

Static evaluation. ABA and NAG tests are conducted on 4 waste rock of different ages (1-year-old, 5-year-old, 1-year-old and 20-year-old) ${ }^{[5,6]}$. First, the pH1:2 and EC1:2 of the samples are tested, i.e. $\mathrm{pH}$ and electric conductivity are tested at 1:2 solid-to-liquid ratio. Testing method: $25 \mathrm{~g}$ samples (grain size $<75$ (screened by 200-mesh sieve)) is weighed and put into a beaker, $50 \mathrm{~g}$ distilled water water is added, mixed evenly and let stand for more than $12 \mathrm{~h}$ (stay overnight) before measuring its $\mathrm{pH}$ and EC.

ABA test: Maximum potential acidity (MPA, $\mathrm{kg} \cdot \mathrm{t}-1$, calculated by $\mathrm{H}_{2} \mathrm{SO}_{4}$ ) should be calculated by formula (1), therein, TS indicates the percentage of sulphur content in the samples.

$\mathrm{MPA}=\mathrm{TS} \times 30.6$ (1)

Test of acid neutralizing capacity (ANC, $\mathrm{kg} \cdot \mathrm{t}^{-1}$, calculated by $\mathrm{H}_{2} \mathrm{SO}_{4}$ ) of samples : 1 or 2 drops of $1: 3 \mathrm{HCl}$ is added in $0.5 \mathrm{~g}$ sample to conduct bubbling level test ${ }^{[6]} ; 2 \mathrm{~g}$ sample is added into a $250 \mathrm{~mL}$ conical flask, $\mathrm{HCl}$ is taken and transferred according to Table $1,20 \mathrm{~mL}$ distilled water is added, the bainmarie is heated $\left(80 \sim 90{ }^{\circ} \mathrm{C}\right)$ until the reaction is finished; while cooled down to room temperature, distilled water is added to $125 \mathrm{~mL}, \mathrm{pH}$ is measured, $\mathrm{NaOH}$ is added until $\mathrm{pH}$ becomes 5,2 drops of $30 \% \mathrm{H}_{2} \mathrm{O}_{2}$ is added and $\mathrm{NaOH}$ droplets are added again, and finally $\mathrm{ANC}$ is calculated.

\section{$\mathrm{ANC}=(\mathrm{Y} \times \mathrm{MHCl} / \mathrm{WT}) \times 49 \quad(2)$}

In the equation, $\mathrm{Y}$ indicates the volume of $\mathrm{HCl}(\mathrm{mL})$ actually consumed, $\mathrm{MHCl}$ indicates $\mathrm{HCl}$ concentration $\left(\mathrm{mol} \cdot \mathrm{L}^{-1}\right)$, and WT indicates sample weight $(\mathrm{g})$.

Table 1 Bubbling level and acid amount and concentration in ANC test

\begin{tabular}{ccccc}
\hline $\begin{array}{c}\text { Reaction } \\
\text { intensity }\end{array}$ & Bubbling level & $\begin{array}{c}\mathrm{HCl} \\
\text { concentration } \\
/\left(\mathrm{mol} \cdot \mathrm{L}^{-1}\right)\end{array}$ & $\begin{array}{c}\mathrm{HCl} \\
\text { volume } / \mathrm{mL}\end{array}$ & $\begin{array}{c}\mathrm{NaOH} \\
\text { concentration } /\left(\mathrm{mol} \cdot \mathrm{L}^{-1}\right)\end{array}$ \\
\hline No reaction & 0 & 0.5 & 4 & 0.1 \\
Mild & 1 & 0.5 & 8 & 0.1 \\
Medium & 2 & 0.5 & 20 & 0.5 \\
Strong reaction & 3 & 0.5 & 40 & 0.5 \\
$\begin{array}{c}\text { Extremely strong } \\
\text { reaction }\end{array}$ & 4 & 1.0 & 10 & 0.5 \\
& $5^{*}$ & 1.0 & 60 & 0.5 \\
\hline
\end{tabular}

Note: * indicates being used in samples (e.g. limestone) with extremely high ANC content $\left(>400 \mathrm{~kg} \cdot \mathrm{t}^{-1}\right.$, calculated by $\mathrm{H}_{2} \mathrm{SO}_{4}$ ).

Net acid generating potential (NAPP, $\mathrm{kg} \cdot \mathrm{t}^{-1}$, calculated by $\mathrm{H}_{2} \mathrm{SO}_{4}$ ) is calculated by Equation (3) ${ }^{[6]}$. NAPP=MPA-ANC (3)

NAG test: $2.5 \mathrm{~g}$ sample is put into a $500 \mathrm{~mL}$ conical flask, $250 \mathrm{~mL} 15 \% \mathrm{H}_{2} \mathrm{O}_{2}$ is added, and let stand overnight; heated until bubbling, and distilled water is added to $250 \mathrm{~mL}$ after cooling, and the measured $\mathrm{pH}$ is $\mathrm{NAG}_{\mathrm{pH}}$. 
Dynamic evaluation. According to literature reports ${ }^{[7]}$, experimental Buchner funnel is customerized, and the dimensions is shown in Fig 1. Residues have 3 repetitions each year, $2 \mathrm{~kg}$ waste rock sample is weighed (ground to $5 \mathrm{~mm}$ ) and placed in a Buchner funnel. A layer of filter paper is arranged at the bottom of the Buchner funnel to prevent clogging of the funnel; in addition, a resistance switch is arranged on the bracket to regulate the lamp brightness so as to control the microclimate temperature within a certain scope; the room temperature is adjusted according to seasons, and the experimental temperature is kept at $(30 \pm 5)^{\circ} \mathrm{C}$ to ensure an even waste rock oxidization rate. 1 cycle is composed of 4 weeks, $100 \mathrm{~mL} \cdot \mathrm{kg}^{-1}$ water is poured on Friday of the first 3 weeks; $400 \mathrm{~mL} \cdot \mathrm{kg}^{-1}$ water is poured on Friday of the 4th week; $1 \mathrm{~L}$ polyethylene bottle is used to collect filtrate, and the volume of filtrate is measured by a volumetric cylinder, around $50 \mathrm{~mL}$ filtrate is taken to test $\mathrm{pH}$ and $\mathrm{EC}$ by $\mathrm{pH}$ meter, and the remaining filtrate is used to test $\mathrm{Cu}^{2+}, \mathrm{Zn}^{2+}, \mathrm{SO}_{4}{ }^{2-}, \mathrm{Fe}^{3+}$ etc by a spectrophotometer. The cycle is repeated, and the test endures 9 cycles from September 2013 to April 2014; the key point of the test is to create a periodic rainfall - oxidation - leaching, which is long enough (4 weeks) to allow oxidation of waste rock and achieve a dynamic research on the law of acid generation of waste rock.

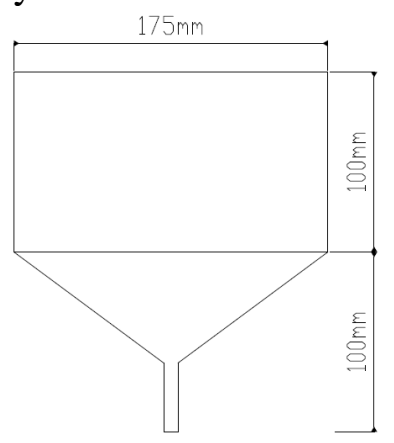

Fig 1 Specifications of experimental Buchner funnel

\section{Results}

Static evaluation. The static evaluation results is shown in Table 2 which indicate that the waste rock of 4 ages comply with the condition of NAPP $>0, \mathrm{NAG}_{\mathrm{pH}}<4.5$, and thus it can be determined that the waste rock of 4 ages have the potential of acid generation. $\mathrm{pH}_{1: 2}$ of waste rock of 4 ages characterizes the acidification condition of waste rock under the current state, 1-year-old waste rock is neutral, indicating it's not oxidized or neutralized due to relatively big ANC though it has been oxidized, the possibility of the latter is higher; however, the 5-year-old, 10-year-old and 20-year-old waste rock have shown relatively strong acidity, therein, $\mathrm{pH}$ of 20 -year-old waste rock is slightly higher.

$\mathrm{EC}_{1: 2}$ of waste rock of different ages respectively represents the existing status of soluble ions in waste rock. EC of 1-year-old waste rock is the highest, indicating there are the most soluble ions in it; the ECs of 5-year-old and 10-year-old waste rock are close to each other; EC of 20-year-old waste rock is the lowest, possibly due to reduction of soluble ions for years of oxidation, leaching and lower-rate acid generation.

Table 2 Results of static evaluation of waste rock of different ages

\begin{tabular}{cccccccc}
\hline $\begin{array}{c}\text { Abandoned } \\
\text { time }\end{array}$ & $\mathrm{pH}_{1: 2}$ & $\begin{array}{c}\mathrm{EC}_{1: 2} / \\
\left(\mu \mathrm{S} \cdot \mathrm{cm}^{-1}\right)\end{array}$ & $\begin{array}{c}\text { Total } \\
\text { sulfur }\end{array}$ & $\begin{array}{c}\mathrm{MPA} / \\
\left(\mathrm{kg} \cdot \mathrm{t}^{-1}\right)\end{array}$ & $\begin{array}{c}\mathrm{ANC} \\
\left(\mathrm{kg} \cdot \mathrm{t}^{-1}\right)\end{array}$ & $\begin{array}{c}\mathrm{NAPP}^{-1} \\
\left(\mathrm{~kg} \cdot \mathrm{t}^{-1}\right)\end{array}$ & $\mathrm{NAG}_{\mathrm{pH}}$ \\
\hline 1 year & 6.85 & 1262 & $23.9 \%$ & 731.34 & 53.9 & 677.44 & 2.54 \\
5 years & 2.24 & 585 & $8.53 \%$ & 261.02 & 9.8 & 251.22 & 2.02 \\
10 years & 2.3 & 565 & $4.76 \%$ & 145.66 & 4.9 & 140.76 & 3.24 \\
20 years & 2.88 & 232 & $2.23 \%$ & 68.24 & 13.65 & 54.59 & 3.76 \\
\hline
\end{tabular}

Dynamic evaluation. Leachate $\mathrm{pH}$ and EC measurement result of waste rock of 4 ages (measured on a monthly basis) are shown in Fig 2. As shown in Fig 2, pH of 1-year-old waste rock has been alkalic, and the variation range is 7.17 7.59; but 5-year-old, 10-year-old and 20-year-old waste rock show acidic, and the variation ranges are 2.23 3.18, 2.11 3.52 and 2.56 3.80 respectively. In general, $\mathrm{pH}$ of 20-year-old waste rock is slightly higher than those of 5-year-old and 10-year-old waste rock. 
This also indicates that the oxidization rate is lower or there isn't acid leaching in the entire experiment period due to bigger ANC; however, $\mathrm{pH}$ of 20-year-old waste rock is higher than those of 5-year-old and 10-year-old waste rock due to higher ANC and lower S content.

The EC variation ranges of 1-year-old and 20-year-old waste rock are limited, but the EC variation of 5-year-old and 10-year-old waste rock are drastic. ECs of 5-year-old and 10-year-old waste rock increase first and decrease later in the first 5 months, possibly due to leaching of the existing metallic ions in the ore on one hand and part of metallic ions are released due to oxidation of the surface-layer ores on the other hand; EC of 10-year-old waste rock increases in the late stage possibly for such reason that waste rock of this age has such structure (including grain size distribution, proportion, etc) that is more favorable for oxidizing reaction, and oxidization reaches the peak in about 10 years. EC of 1-year-old waste rock is close to $\mathrm{EC}_{1: 2}$, possibly because its low internal acidity isn't favorable for the release of metallic ions and this leads to lower EC.
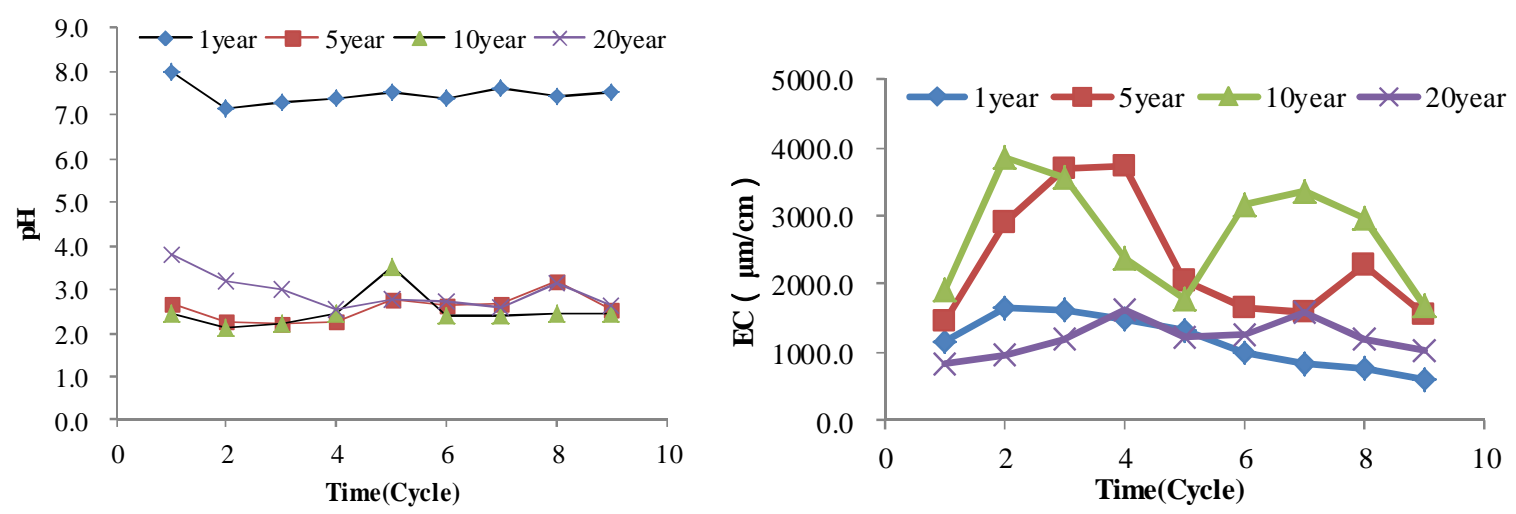

Fig 2 Leachate pHs and ECs of waste rock of different ages

Correlation analysis is conducted on pHs and ECs of waste rock of 4 different ages (including repetition) each month, and the result indicates $\mathrm{pHs}$ of the waste rock of 4 ages show remarkable negative correlation with ECs, and the correlation coefficient $r$ is $-0.471(p<0.05),-0.769(p<0.01)$, $-0.736(p<0.01)$ and $-0.868(p<0.01)$ respectively; it's identical with the previous research results ${ }^{[8]}$.

As shown in Fig 3, the cumulative released quantities of $\mathrm{Cu}^{2+}$ of 5-year-old and 10-year-old waste rock are higher, that of 1-year-old is the lowest, and that of 20-year-old is relatively high. It's possibly because the 1-year-old waste rock hasn't been oxidized, or the neutralization of alkaline compositions avoided generation of acid though oxidized; however, 5-year-old and 10-year-old waste rock generate large quantity of acid, and as a result, $\mathrm{Cu}^{2+}$ is easy to leach. $\mathrm{Cu}^{2+}$ release of 1-year-old waste rock is $0.01 \sim 0.03 \mathrm{mg} \cdot \mathrm{L}^{-1}, 0.12 \sim 1.11 \mathrm{mg} \cdot \mathrm{L}^{-1}$ for 5-year-old waste rock, and $0.16 \sim 0.95 \mathrm{mg} \cdot \mathrm{L}^{-1}$ for 10 -year-old waste rock, all of them are close to or above the secondary standard for sewage discharge stipulated by the state $\left(1 \mathrm{mg} \cdot \mathrm{L}^{-1}\right)$.

Accumulative quantities of $\mathrm{Zn}^{2+}$ and $\mathrm{Cu}^{2+}$ release show the same law, i.e. those of 5-year-old, 10-year-old and 20-year-old waste rock are higher than that of 1-year-old waste rock, the monthly $\mathrm{Zn}^{2+}$ release quantity of 1-year-old waste rock is relatively stable, similar to the release trend of 5-year-old, 10-year-old and 20-year-old waste rock. Therein, $\mathrm{Zn}^{2+}$ release quantity of 5-year-old waste rock is $0.11 \sim 1.47 \mathrm{mg} \cdot \mathrm{L}^{-1}$, and $0.11 \sim 1.89 \mathrm{mg} \cdot \mathrm{L}^{-1}$ for 10 -year-old waste rock, close to the primary standard for sewage discharge $\left(2 \mathrm{mg} \cdot \mathrm{L}^{-1}\right)$.

On the curve of accumulative $\mathrm{SO}_{4}{ }^{2-}$ release of different waste rock, corresponding $\mathrm{SO}_{4}{ }^{2-}$ leaching quantity may increase in the first month due to the existence of sulfate, later, 5 years, $\mathrm{SO}_{4}{ }^{2-}$ leaching quantities of 5-year-old and 10-year-old waste rock continue to increase due to relatively high $\mathrm{S}$ content. This indicates this period of time is the peak of oxidization.

Among $\mathrm{Fe}^{3+}$ leaching quantities of waste rock of 4 different ages, those of 10 -year-old and 5 -year-old waste rock are the highest. This is relevant to the oxidation state. The oxidation rate of 5-year-old and 10-year-old waste rock are relatively high and $\mathrm{pH}$ is relatively low, thus favorable for $\mathrm{Fe}$ leaching; however, the oxidation rate of 1-year-old waste rock is relatively low, $\mathrm{pH}$ is relatively high, thus more favorable for generation of Fe hydroxide, and Fe leaching quantity is relatively small. The maximum leached $\mathrm{Fe}^{3+}$ concentrations of 1-year-old, 5-year-old, 10-year-old and 20-year-old waste 
rock are $0.29,491,1130$ and $177 \mathrm{mg} \cdot \mathrm{L}^{-1}$ respectively; although there isn't any express standard to limit the $\mathrm{Fe}^{3+}$ content in water, excessive $\mathrm{Fe}^{3+}$ may generate iron hydroxide which makes the water turn red brown, and causes "Red Dragon Disaster" ${ }^{[9]}$.
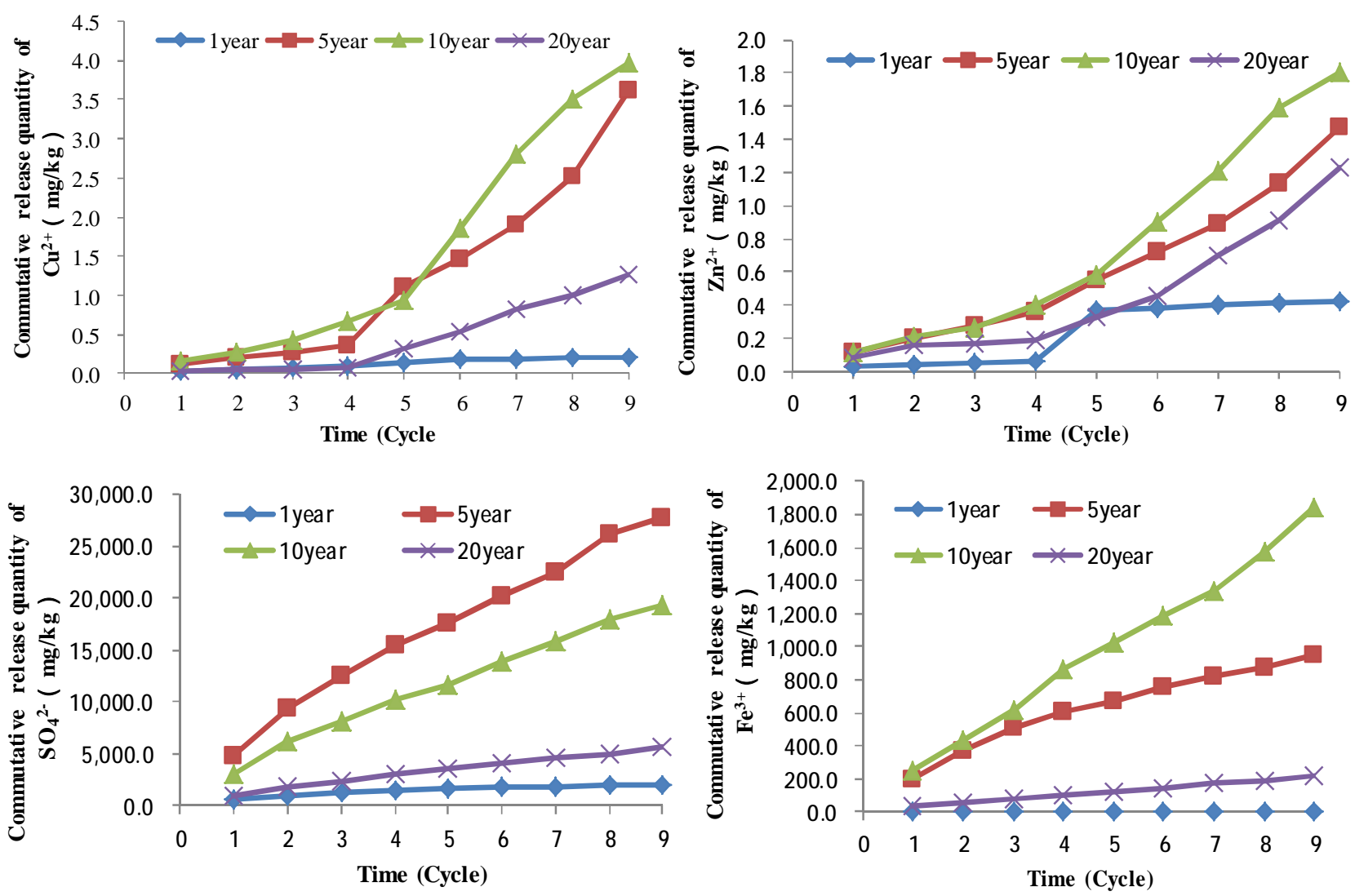

Fig 3 Commutative release quantities of $\mathrm{Cu}^{2+}, \mathrm{Zn}^{2+}, \mathrm{SO}_{4}{ }^{2-}$ and $\mathrm{Fe}^{3+}$

It's discovered by testing fluoride content in lixivium that the sequence of waste rock of different ages is 1 year $>10$ years $>20$ years $>5$ years. As fluorides existing in mines are easy to leach, the leaching quantity of 1-year-old waste rock is big due to high F content; this also means that leaching of fluorides is irrelevant to the oxidization state, but only related to the existing state of fluorides in ores. The range of fluoride contents in waste rock of 4 ages is $0.2 \sim 1.0 \mathrm{mg} \cdot \mathrm{L}^{-1}$, a reasonable range, and thus has no influence on the ambient water environment ${ }^{[10]}$.

$\mathrm{Cr}, \mathrm{Cd}, \mathrm{Hg}$ and other metallic ions are below the detection limit, or in trace amount, and thus pose no threat to the environment. $\mathrm{Pb}$ detection result indicates that $\mathrm{Pb}$ content is higher only in 10 -year-old waste rock, fluctuating within the range of $0.2 \sim 0.4 \mathrm{mg} \cdot \mathrm{L}^{-1}$, and those of waste rock of 3 other ages are below the detection limit $\left(0.2 \mathrm{mg} \cdot \mathrm{L}^{-1}\right)$.

\section{Discussion}

Leaching has accelerating effect on oxidation of waste rock, and the research findings show the precipitation and temperature are in positive correlation with oxidation rate of waste rock containing sulfur minerals, but such high precipitation and temperature are not available in natural condition. As distilled water is adopted for leaching, acidification and release of heavy metal may be relatively slow compared with acidic leaching ${ }^{[11-13]}$. Waste rock of 4 different ages don't have time continuity in a strict sense, but are only the products of the same type of waste rock in different stacking conditions, but the continuity of approximate chemical compositions should be satisfied.

The accumulative release curve of each ion isn't identical with the previous research results ${ }^{[11-13]}$, this may be attributed to relatively mass use of waste rock in this test $(2 \mathrm{~kg})$ and relatively high sulfur content. However, mass accumulation of waste rock complies with the stacking state under actual 
condition. During the oxidation process, surface waste rock can be oxidized easily, but oxidation of waste rock in lower layers is slow because oxygen is difficult to enter ${ }^{[14]}$. During late-stage experiment, release of various metallic ions shows an accelerated release trend after undergoing a short slowing period with the improvement of stability of oxidation rate, rather than continuous steady increase.

pHs and ECs of 5-year-old and 10-year-old waste rock indicate that their initial internal acid generating states are close to each other, and leaching test also proved this; the oxidation rates of 5-year-old and 10-year-old waste rock are relatively high, and ion release quantities are relatively big. In contrast, the $\mathrm{SO}_{4}{ }^{2-}$ release quantity of 5-year-old waste rock is higher than that of 10-year-old waste rock, however, the release quantities of $\mathrm{Cu}^{2+}, \mathrm{Zn}^{2+}, \mathrm{Fe}^{3+}$, etc are higher than those of the former. This may be contributed to high sulfur content of 5-year-old waste rock, and meanwhile, to relatively big $\mathrm{SO}_{4}{ }^{2-}$ release due to relatively high sulfate mineral content in waste rock, but the existing modes of $\mathrm{Cu}^{2+}, \mathrm{Zn}^{2+}, \mathrm{Fe}^{3+}$ and other ions in 10-year-old waste rock are more easy to leach ${ }^{[15]}$. The initial $\mathrm{pHs}$ of 1-year-old waste rock and 20-year-old waste rock indicate that the former doesn't generate acid, but the latter has been acidized, but the ECs and release quantities of the two are similar. Although the sulfur content of 1-year-old waste rock is high, the content of neutral substance is also high, as a result, no acid is generated even it's oxidized, and leaching quantity of each ion is little; as the sulfur content of 20-year-old waste rock is less, the oxidization rate is limited, and the leaching quantity of each ion is less as a result.

According to the variation of sulfur content and actually measured $\mathrm{SO}_{4}{ }^{2-}$ and other ions, the sulfur content reduces the most within 1 5 years, indicating this period of time is the peak of oxidization; however, 1-year-old waste rock doesn't generate acid during the test, possibly due to relatively strong neutralization in waste rock, and this also indicates that a relatively drastic acid generating process may occur at a later time. The peak drops within the 1 10 period, but 20-year-old waste rock still shows certain acid generation capability. And acid will continue to be generated in a relatively long future time if estimated in accordance with the current acid generation rate. This also illustrates the chronicity of acid generation.

During mine waste rock stacking, it's advised to place fresh waste rock on the top layer to effectively reduce generation of acid waste water ${ }^{[16]}$; if dry covering method is employed to prevent acid waste water, it's advised to add some waste rock of younger age and not generating acid into a single layer or multiple layers; during waste rock dump reconstruction, the acid waste water generating intensity of waste rock should be taken into consideration; and a long-term acid generating model can be further established for waste rock to provide a foundation for numerical simulation during the work of acid waste water prevention. It's predictable that acid generation must last a very long period of time, but its environmental impact cannot be overlooked though the acid generating rate is slowing down, because the quantity of waste rock is huge.

\section{Conclusions}

1) The 1-year-old, 5-year-old, 10-year-old and 20-year-old waste rock of Dexing Copper Mine selected for the test have the potential of acid generation, and the 5-year-old, 10-year-old and 20-year-old waste rock have generated acid, the $\mathrm{pH}$ of 1-year-old waste rock has been greater than 7 during the testing period, the acid generating states of 5-year-old and 10-year-old waste rock are close to each other, but the acid generating rate of 20 -year-old waste rock is relatively low. pHs of waste rock of different ages have negative correlation with EC.

2) $\mathrm{Cu}^{2+}, \mathrm{Zn}^{2+}, \mathrm{Fe}^{3+}, \mathrm{SO}_{4}{ }^{2-}$ and other ions show relatively high release among the 5-year-old and 10-year-old waste rock, therein, $\mathrm{Cu}, \mathrm{Zn}$, etc exceed the specified standard, and impose certain impact on the environment.

3) As ANC of 1-year-old waste rock is relatively big and the oxidation rate is relatively low, no acid is generated; the acid generating rate of 5-year-old and 10-year-old is stable; the acid generating rate of 20 -year-old waste rock is reduced due to lowering sulfur content. And it can be inferred that there is a high-rate acid generating stage in 1 5 years, therefore, the research on the acid generating process of 
waste rock can be deemed as such a process " no acid generation - high-rate acid generation - stable acid generation - lower-rate acid generation".

\section{Acknowledgements}

The project was financially supported by the International Technology Cooperation Special Project (2012DFA90500): Research on Key Technology Cooperation for Comprehensive Improvement to Acidic Pollution in Metallic Mine Dump.

\section{References}

[1] Qun Yang, Ping Ning, Fangyuan Chen, et al. Status Quo and Prospect of the Treatment Technology for Acid Mine Drainage, Metal mine. 1 (2009) 131-134. (In Chinese)

[2] Yuanhong Luo, Liangqi Lei, Yaohui Chang. Discussion on Acidic Mining Drainage Production and Prevention in Carbonate Rock Area, Environmental Science and Management. 7(2011)81-83. (In Chinese)

[3] Lei Wang, Zeqin Li, Lei Jiang. Acidic Mine Waste Water Hazards and Countermeasures Research, Environmental Science and Management. 10(2009)82-84. (In Chinese)

[4] Weijun Qiu. Prevention and control of acid wastewater produced in metallic mines, Gold. 3(2014)73-76. (In Chinese)

[5] Jinwen Li, Huiming Li, Yongheng Chen. The static prediction and criteria of acid rock drainage, Journal of Guangzhou University(Natural Science Edition). 4(2008)60-63. (In Chinese)

[6] Zengpin Ning, Tangfu Xiao, LianBi Zhou, et al. Prediction of Acid Rock Drainage (ARD) Generation Potential in an Antimony Mining Area, Earth and Environment. 3(2009) 249-253. (In Chinese)

[7] Othmani M A,Souissi F,Benzaazoua M,et al. The geochemical behaviour of mine tailings from the Touiref $\mathrm{Pb}-\mathrm{Zn}$ district in Tunisia in weathering cells leaching tests, Mine Water and the Environment. $1(2013) 28-41$.

[8] Jinwen $\mathrm{Li}$, Nan Chen, Huiming $\mathrm{Wu}$, et al. Study on acid generation potential and process useing kinetic flood leaching and static methods for Yunfu Pyrite, Environmental Chemistry. 1(2010)101-104. (In Chinese)

[9] Zhao Ling, Wang Rongxin, Li Guan, Chen Ming, et al. Processing of Acid Mine Drainage and Development Prospect of Source Control Technology, Metal mine. 7(2009) 131-135. (In Chinese)

[10]Zhengmiao Xie, Weihong Wu, Jianmin Xu. Translocation and transformation of fluorides in the environment and their biological effects, Chinese Journal of Environmental Engineering. 2(1999)40-53. (In Chinese)

[11] Wen Yuan, Hailan Fang, Youcai Zhao.Experiment Study of Heavy Metal Washing Away in Aged Waste, Environmental Sanitation Engineering. 2(2007) 34-38. (In Chinese)

[12] Xianzhen Sheng, Yuanyuan Li, Qiuxiang Zhao. Experimental Study on the Release Properties of Copper and Zine in Tailings under Simulated Acid Rain, Guangdong Chemical Industry. 6(2011) 142-144. (In Chinese)

[13]Nan Li, Jie Chi. Speciation of heavy metals in the ore scattering in the harbor yard and their simulated acid rain leaching behaviors, Journal of Safety and Environment. 6(2013)99-102. (In Chinese) 
[14] Na Zhang, Yuanyi Zhao, Guangdi Zhang, et al. Environmental Effect of Heavy Metal Elements in Dexing Copper Mine,Jiangxi Province, Acta Geologica Sinica.4 (2008): 562-576. (In Chinese)

[15]Zhaohui Guo, Changyong Huang, Bohan Liao. Effects of simulated acid rains on $\mathrm{Cd}, \mathrm{Cu}$ and $\mathrm{Zn}$ release and their form transformation in polluted soils, Chinese Journal of Applied Ecology. 9(2003): 1547-1550. (In Chinese)

[16] Yunzhang Rao, Shuitai Xu, Jianping Pan, et al. Study on Distribution Rules of Acid Mine Drainage and Heavy Metal Pollution of Sulphide Mineral in the Waste Rock Site, Journal Os Southern Institute of Metallurgy. 5(2003): 90-94. (In Chinese) 